\title{
Intra-articular Injection of Local Anaesthetic and Corticosteroid: A Potentiation Effect of Pain Relief in Grade IV Gonarthrosis and an Alternative to Arthroplasty Operations
}

\author{
Aykut Sigirci*
}

\section{Aykut Sigirci* \\ Orthopeadic Consultant, Department of Orthopaedics, Evliya Celebi Train- ing and Research Hospital, Kutahya, TURKEY. \\ *Correspondence \\ Aykut Sigirci \\ Department of Orthopaedics, Evliya \\ Celebi Training and Research Hospital, Kutahya, TURKEY. \\ Phone: +905077834236 \\ Email: aykutsigirci@yahoo.com \\ History \\ - Submission Date: 25-12-2019; \\ - Review completed: 22-02-2020; \\ - Accepted Date: 27-03-2020.}

DOI : 10.5530/ijcep.2020.7.1.3

\section{Article Available online}

http://www.ijcep.org

Copyright

(C) 2020 Phcog.Net. This is an openaccess article distributed under the terms of the Creative Commons Attribution 4.0 International license.

\begin{abstract}
Background and Aim: There are few nonsurgical options for treatment of grade IV knee osteoarthritis. This randomised controlled clinical trial was performed to evaluate the efficacy and safety of intra-articular injection of local anaesthetic and corticosteroid for pain management in patients with grade IV osteoarthritic knee joints. Methods: A total of 240 patients with grade IV osteoarthritic knee joints were enrolled and separated into four groups. They were administered different intra-articular injections: Group A received local anaesthetic (prilocaine); Group B received methylprednisolone; Group C received methylprednisolone+ saline; and Group D received methylprednisolone+prilocaine. The number of pain-free days following injection was recorded. Results: The mean number of pain-free days was $3.7 \pm 0.2$ days in Group A vs. $62.1 \pm 0.3$ days in Group B vs. $75.5 \pm 0.8$ days in Group $C$ vs. $157 \pm 0.5$ days in Group $D(P<0.05)$. Patients were asked to report to the clinic if pain recurred and the same injection was repeated. After the second injection, once again, the number of pain-free days was significantly higher in Group D (161 days) than in the other groups. Adverse events encountered included syncope $(n=14)$ and cellulitis at injection site $(n=2)$. Conclusion: Intra-articular combination of methylprednisolone and prilocaine appears to be a safe and effective method for potentiating pain relief in grade IV knee osteoarthritis. The injection can be repeated at intervals to provide a permanent pain-free knee for patients. Key words: Osteoarthritis, Intra-articular, Local anesthetic, Steroid, Arthroplasty.
\end{abstract}

\section{INTRODUCTION}

Osteoarthritis (OA) is a common cause of morbidity in the elderly and patients often suffer years of pain and disability. Knee pain secondary to OA accounts for up to $30 \%$ of visits to primary care physicians. $\mathrm{OA}$ is characterized by an imbalance between the synthesis and degradation of articular cartilage and subchondral bone and is accompanied by capsular fibrosis, osteophyte formation and variable grades of inflammation of the synovial membrane. ${ }^{[1]}$ The incidence of symptomatic OA increases with age and, at all ages, women are more commonly affected than men. ${ }^{[2]}$

The most effective treatment for grade 4 osteoarthritis is arthroplasty. When the patient is unwilling or unsuitable for surgery, oral paracetamol and nonsteroidal anti-inflammatory drugs (NSAIDs) may provide temporary relief; however, these drugs cannot fully control the pain of advanced knee OA and their prolonged use can lead to gastrointestinal and cardiovascular side effects. Intra-articular injection is a useful alternative; it can provide pain relief, improve quality of life and help postpone surgical intervention. In our orthopaedic practice, we routinely use this treatment for grade 4 gonarthrosis patients who refuse or are unsuitable for surgery. The pain relief is surprisingly good and patients often ask for a repeat injection after several months. However, there are few well-designed, controlled studies that have evaluated the use of intra-articular corticosteroids and local anaesthetics in the treatment of knee OA. ${ }^{[3]}$ The aim of this randomised controlled study was to determine the efficacy and safety of intra-articular injection local anaesthetic+corticosteroid in patients with grade IV OA of the knee.

\section{MATERIALS AND METHODS}

Study participants were selected from among knee OA patients attending our orthopaedic clinic during 2014-2016. Patients were eligible for enrolment if they 1) had grade 4 osteoarthritis of the knee, 2) were unwilling to undergo arthroplasty or had contraindication for surgery and 3) were willing to accept intra-articular injection. Patients with rheumatoid arthritis, diabetes mellitus, thyroid abnormalities, abnormal pain responses and major psychiatric disorders were excluded. A total of 240 patients were consecutively enrolled. They were randomized into

Cite this article: Sigirci A. Intra-articular Injection of Local Anaesthetic and Corticosteroid: A Potentiation Effect of Pain Relief in Grade IV Gonarthrosis and an Alternative to Arthroplasty Operations. Int J Clin Exp Physiol. 2020;7(1):11-3. 
four groups according to their order of recruitment into the study. Thus, patient number 1 was allocated into group A, patient number 2 into group $B$, patient number 3 into group $C$ and patient number 4 into group 4. This cycle was repeated until there were 60 patients in each group.

All intra-articular injections were administered under sterile conditions by the author. For the procedure, the patient was seated on the examination table, with the knee in $90^{\circ} \mathrm{C}$ flexion. The injection site was cleaned with povidone-iodine. Approach was through the anterolateral portal of the knee. Group A patients received $10 \mathrm{cc}$ of $2 \%$ prilocaine; group B patients received a flacon of $40 \mathrm{mg}$ methylprednisolone; group $\mathrm{C}$ received a flacon of methylprednisolone $+10 \mathrm{cc}$ of saline; and group D received a flacon of methylprednisolone+ $10 \mathrm{cc}$ of prilocaine. After injection, no additional medications, including anti-inflammatory drugs, were prescribed. The patients were requested not to take any oral medication and to attend follow-up without fail. Cell phone numbers and addresses were recorded so that they could be contacted if necessary.

Written informed consent was obtained from all patients before the procedure.

Primary outcome was the number of pain-free days following intraarticular injection. This was recorded for each patient. The patients were told to report to the clinic if they experienced pain again. If the patient did not report to the clinic even 5 months after the first injection, they were contacted to determine if they had experienced pain. A total of 53/60 (88.3\%) in group A, 57/60 (95\%) in group B, 59/60 (98.3\%) in group C and 57/60 (95\%) in Group D completed the study, reporting back to the polyclinic when pain recurred. A total of 11 patients were lost to follow-up. Three patients (1 patient each from group A, group B and group D) opted for arthroplasty. When patients experiencing recurrence of pain came for their second clinic visits, they were administered the same injection that they had received earlier and, again, advised to report back if pain recurred. The pain-free duration following the second injection was recorded. The duration of pain-free intervals was compared between the groups.

\section{Statistical Analysis of Data}

Data were summarized as means \pm standard deviation. The Mann-Whitney $U$ test and Kruskal-Wallis test were used for comparisons between groups. Statistical significance was at $P \leq 0.05$.

\section{RESULTS}

A total of 240 patients were enrolled in the study, with 60 patients per group. Mean age, mean weight and gender composition were comparable between the groups (Table 1).

The mean pain-free duration after the first injection was $3.7 \pm 0.2$ days when only local anaesthetic was used (Group A) and $62.1 \pm 0.3$ days when only corticosteroid was used (Group B). When the two drugs were combined (Group D), pain relief lasted for $157 \pm 0.8$ days, indicating potentiation of effect. The pain-free intervals after the second injections were similar to that after the first injections in all groups and, once again, group D had the longest pain-free interval. With two intra-articular

Table 1: Demographic features of patients in the four groups.

$\begin{array}{cccccc} & \text { Group A } & \text { Group B } & \text { Group C } & \text { Group D } & \boldsymbol{P} \\ \begin{array}{c}\text { Mean age } \\ \text { (years) }\end{array} & 65.6 \pm 1.2 & 63.7 \pm 1.8 & 64.68 \pm 0.9 & 63.42 \pm 0.4 & >0.05 \\ \begin{array}{c}\text { Mean weight } \\ (\mathrm{kg})\end{array} & 82.1 \pm 0.8 & 92.3 \pm 2.1 & 87.8 \pm 1.6 & 97.1 \pm 0.5 & >0.05 \\ \begin{array}{c}\text { Gender } \\ \text { (male/female) }\end{array} & 7 / 53 & 6 / 54 & 10 / 50 & 4 / 56 & >0.05 \\ & & & & & \end{array}$

Table 2: Mean number of pain-free days in the four groups.

\begin{tabular}{cccccc} 
& Group A & Group B & Group C & Group D & $P$ \\
$\begin{array}{c}\text { Pain-free days after } \\
\text { first injection }\end{array}$ & $3.7 \pm 0.2$ & $62.1 \pm 0.3$ & $75.5 \pm 0.8$ & $157 \pm 1.2$ & $<0.05$ \\
$\begin{array}{c}\text { Pain-free days after } \\
\text { second injection }\end{array}$ & $5.3 \pm 1.3$ & $75.3 \pm 0.7$ & $83.1 \pm 1.2$ & $161.8 \pm 2.3$ & $<0.05$ \\
$\begin{array}{c}\text { Total pain-free } \\
\text { days }\end{array}$ & $9 \pm 1.5$ & $137.4 \pm 1$ & $158.6 \pm 2$ & $318.8 \pm 3.5$ & $<0.05$ \\
\hline
\end{tabular}

injections, 13 patients in group D achieved complete pain relief for 1 year (Table 2).

The combination of corticosteroid and saline (group C) also produced a slight increase of the pain-free duration to 75.5 days. However, the improvement over that achieved with corticosteroid alone (75.5 days vs. 62.1 days) was not statistically significant $(P>0.05)$. The slightly enhanced effect was likely due to a simple dilution effect of saline on intraarticular enzymes and debris.

\section{DISCUSSION}

Despite the immense impact that OA has on the lives of many people there are very few effective, nonsurgical treatments available. ${ }^{[4]}$ One commonly used treatment is intra-articular injection of corticosteroid and local anaesthetic. This study is the first long-term, prospective, randomized controlled trial to examine the safety and efficacy of intraarticular injection of different combinations of drugs in grade IV knee OA.

Thorn, in 1940, was the first to report the use of intra-articular corticosteroid for treatment of knee OA. In 1951, Hollander confirmed the effectiveness of the practice. ${ }^{[5]}$ Since then it has been widely used and many international guidelines now advocate the use of intra-articular corticosteroids for painful knee OA. Corticosteroids can provide substantial short-term pain relief for up to 8 weeks and some authors suggest that the benefits may last as long as 6 months. ${ }^{[6]}$

Corticosteroids have both anti-inflammatory and immunosuppressive effects. They act on nuclear steroid receptors and interrupt the inflammatory immune cascade at several levels. They reduce vascular permeability; decrease erythema, swelling and tenderness; and inhibit accumulation of inflammatory cells and inflammatory mediators. Corticosteroids are reported to reduce prostaglandins production and increase vasodilatation when injected into the knee joint. ${ }^{[7]}$

Dieppe et al. found that although pain relief was significantly better with intra-articular corticosteroid than with placebo, the benefit was short lived. ${ }^{[8]}$ However, depot formulations such as methylprednisolone persist at the injection site for long periods. According to Valtonen et al. ${ }^{[9]}$ Matzkin et al. ${ }^{[10]}$ and Juni et al. ${ }^{[11]}$ long-acting corticosteroids might provide pain relief for up to 6 months. In our study, however, the mean pain-free duration in patients receiving corticosteroid injection alone was only for 2 months.

A common method for potentiating the effect of intra-articular injection is to combine a depot form of corticosteroid (for its anti-inflammatory effect) with a local anaesthetic (for providing immediate analgesia). Intra-articular local anaesthetic provides immediate pain relief that lasts 4-5 h. In addition, local anaesthetic can decrease sensitization, which is a feature of chronic or persistent pain and thereby prolong the treatment effect beyond the normal pharmacological duration of action. ${ }^{[12]}$

In this study each injection of the combination of local anaesthetic and corticosteroid provided pain relief for about 5 months. Repeated intraarticular injection of this combination could be an effective long-term management option in patients unwilling or unable to undergo surgical 
Sigirci: Intra-articular injection for OA pain relief

treatment. Although there is no conclusive evidence on the ideal treatment frequency, it is generally recommended to keep the injections limited to once every 3 months. ${ }^{[13]}$

Sahin et al. reported that significant pain reduction was achieved for 2 years after injection of corticosteroid + local anaesthetic into the sacroiliac joint. ${ }^{[14]}$ In another study, $82 \%$ of patients with De Quervain tendinitis treated with corticosteroid injections remained symptom free for 12 months. ${ }^{[15]}$ These results were better than that in our study, but this may be because the target was soft tissue and not a joint.

The prolonged effect of intra-articular injection may be due to osteoarthritic cartilage morphology. Healthy adult cartilage is devoid of blood vessels and nerve endings. Osteoarthritic cartilage, in contrast, may be invaded by blood vessels and nerves from the subchondral bone. Hypertrophic chondrocyte differentiation may underlie cartilage angiogenesis in osteoarthritis. ${ }^{[16]}$ In osteochondral angiogenesis, subchondral bone marrow is replaced by fibro vascular tissue expressing vascular endothelial growth factor and there is increased expression of nerve growth factor within vascular channels. ${ }^{[17]}$ These factors, especially the nerve growth into osteoarthritic cartilage, may explain the potentiation of pain relief seen with the use of a combination of local anaesthetic and corticosteroid.

Hollander injected corticosteroids on 1034 osteoarthritic knees and reported that $80 \%$ of patients achieved pain relief for $1-4$ weeks. ${ }^{[5]} \mathrm{A}$ systematic review of intra-articular corticosteroid injections for treatment of knee OA concluded that the beneficial effect of treatment commenced 1 week after injection and lasted for 3-4 weeks. ${ }^{[18]}$ In our study, however, we observed 2 months of pain relief with each injection of depot corticosteroid.

Adverse effects following intra-articular corticosteroid injections have included septic arthritis, post injection flare, local tissue atrophy, tendon rupture, cartilage damage, flushing and increased serum glucose level. Only a few mild adverse events were encountered in our series; these included syncope $(n=14)$ and cellulitis at the injection side $(n=2)$. These patients were withdrawn from the study and replaced by other patients.

\section{CONCLUSION}

Intra-articular corticosteroid and local anaesthetic injection appears to be a safe and effective surgery-sparing procedure. An intra-articular injection of a combination of corticosteroid and local anaesthetic performed twice a year may be sufficient to provide a painless knee for patients unwilling or unsuitable for knee surgery. Potentiation of pain relief with the use of the combination, the low cost of treatment and the few risks make this an attractive alternative to arthroplasty in selected patients.

\section{ACKNOWLEDGEMENT}

Nil.

\section{CONFLICT OF INTEREST}

The authors declare that they have no conflict of interest.

\section{ABBREVIATIONS}

OA: Osteoarthritis; NSAID: Non-steroidal Anti-inflammatory Drugs.

\section{REFERENCES}

1. Tehranzadeh J, Booya F, Root J. Cartilage metabolism in osteoarthritis and the influence of visco supplementation and steroid: a review. Acta Radiol. 2005;46(3):288-96.

2. Oliveria SA, Felson DT, Reed JI, Cirillo PA, Walker AM. Incidence of symptomatic hand, hip and knee osteoarthritis among patients in a health maintenance organization. Arthritis Rheum. 1995;38(8):1134-41.

3. Saunders SF. Injection techniques in musculoskeletal medicine: a practical manual for clinicians in primary and secondary care. $4^{\text {th }}$ ed. Edinburgh: Churchill Livingstone Elsevier. 2013.

4. Colen S, Bekerom MPJ, Bellemans J, Mulier M. Comparison of intra-articular injections of hyaluronic acid and corticosteroid in the treatment of osteoarthritis of the hip in comparison with intra-articular injections of bupivacaine. Design of a prospective, randomized, controlled study with blinding of the patients and outcome assessors. BMC Musculoskeletal Disorders. 2010;11(1):264.

5. Hollander JL. The local effects of compound $F$ (hydrocortisone) injected into joints. Bull Rheum Dis. 1951;2(2):3-4.

6. Arroll B, Goodyear-Smith F. Corticosteroid injections for osteoarthritis of the knee: meta-analysis. BMJ. 2004;328(7444):869.

7. Tran J, Schwarzkopf R. Local infiltration anesthesia with steroids in total knee arthroplasty: a systematic review of randomized control trials. J Orthop. 2015;12(Suppl 1):44-50.

8. Dieppe PA, Sathapatayavongs B, Jones HE, Bacon PA, Ring EF. Intra-articular steroids in osteoarthritis. Rheumatol Rehabil. 1980;19(4):212-7.

9. Valtonen EJ. Clinical comparison of triamcinolonehexacetonide and betamethasone in the treatment of osteoarthrosis of the knee-joint. Scand J Rheumatol. 1981;41:S1-7.

10. Matzkin EG, Curry EJ, Kong Q, Rogers MJ, Henry M, Smith EL. Efficacy and treatment response of intra-articular corticosteroid injections in patients with symptomatic knee osteoarthritis. J Am Acad Orthop Surg. 2017;25(10):703-14.

11. Jüni $P$, Hari R, Rutjes AW, Fischer R, Silletta MG, Reichenbach $S$, et al. Intraarticular corticosteroid for knee osteoarthritis. Cochrane Database Syst Rev. 2015;2015(10):CD005328

12. MacMahon PJ, Eustace SJ, Kavanagh EC. Injectable corticosteroid and loca anesthetic preparations: a review for radiologists. Radiology. 2009;252(3):647-61.

13. Law TY, Nguyen C, Frank RM, Rosas S, McCormick F. Current concepts on the use of corticosteroid injections for knee osteoarthritis. Phys Sportsmed. 2015;43(3):269-73.

14. Sahin O, Harman A, Akgün RC, Tuncay IC. An intraarticular sacroiliac steroid injection under the guidance of computed tomography for relieving sacroiliac joint pain: a clinical outcome study with two years of follow-up. Archives of Rheumatology. 2012;27(3):165-73.

15. Earp BE, Han $\mathrm{CH}$, Floyd WE, RozentalTD, Blazar PE. De Quervaintendinopathy: survivorship and prognostic indicators of recurrence following a single corticosteroid injection. Hand Surg Am. 2015;40(6):1161-5.

16. Walsh DA, McWilliams DF, Turley MJ, Dixon MR, Fransès RE, Mapp PI, et al. Angiogenesis and nerve growth factor at the osteochondral junction in rheumatoid arthritis and osteoarthritis. Rheumatology. 2010;49(10):1852-61.

17. Suri S, Gill SE, Massena SCD, Wilson D, McWilliams DF, Walsh DA. Neurovascular invasion at the osteochondral junction and in osteophytes in osteoarthritis. Ann Rheum Dis. 2007;66(11):1423-8.

18. Godwin M, Dawes M. Intra-articular steroid injections for painful knees Systematic review with meta-analysis. Can Fam Physician. 2004;50(2):241-8.

Cite this article: Sigirci A. Intra-articular Injection of Local Anaesthetic and Corticosteroid: A Potentiation Effect of Pain Relief in Grade IV Gonarthrosis and an Alternative to Arthroplasty Operations. Int J Clin Exp Physiol. 2020;7(1):11-3. 